\title{
RAINFALL AND THE WIDTH OF ANNUAL RINGS IN PLANTED WHITE SPRUCE
}

\author{
BY DANIEL GAGNON ${ }^{1}$
}

Daniel Gagnon was born in Trois-Rivières, Quebec, in 1914 where he received his B.A. degree in 1936. He worked for the Provincial Government, Department of Public Works, until 1940 when he joined the R.C.A.F. Discharged in 1946 he enrolled in the Faculty of Forestry at Laval University, Quebec, where he graduated as a forest engineer in 1950. In 1953 he received an M.F. from Laval, majoring in plant physiology. During the summers 1947 to 1950 he worked as a cruiser for different firms throughout the province of Quebec. In 1950 he joined the Forestry Branch, now the Department of Forestry, as a research officer.

\section{ABSTRACT}

The influence of monthly rainfall on the mean annual ring width in a 31-year-old plantation of white spruce, Picea glauca (Moench) Voss, on sandy soils near Grand'Mère, Quebec, was studied. Analysis carried out on 43 dominant trees growing without competition on a very poor dry site of coarse material indicated that current mean annual ring width is closely related to the mean monthly precipitation during June, July and August of the preceding year. Although this relationship was evident for the past 18 years, the possibility that other factors may act concurrently is recognized.

\section{INTRODUCTION}

During the last few decades there has been an ever-increasing stream of literature dealing with rainfall and tree growth relations, and published conclusions range from NO CORRELATION to UNQUESTIONABLE CORRELATION.

The views of a group of specialists on the difficulties involved in correlating growth with rainfall were expressed at a conference held at the University of California in August 1940. From the report made by Sampson and Glock (1942), it would appear that the issue as to whether or not rainfall influences ring growth was not cleared. According to Glock (1955), "the results achieved during the past decade have been in general little or no better than those reported during the second decade past. Correlations have been more widespread but no more fundamental". However, some results reported since (Tryon et al., 1957; Fritts, 1958; Weihe, 1959; Kramer and Kozlowski, 1960) tend to demonstrate that the beneficial effects of rainfall on the annual ring width vary with tree species and depend not only upon the local soil conditions but also, and mainly, upon the period of its occurrence.

The purpose of the present investigation was to test to what degree rainfall of the previous growing season could, by influencing the soil moisture, affect current ring width increment of white spruce growing under local conditions.

\footnotetext{
${ }^{1}$ Research Officer, Forest Research Branch, Department of Forestry, Quebec, P.Q.
} 


\section{The Area}

\section{EXPERIMENTAL Details}

The experimental area is located in a plain east of the St. Maurice River, at about 6 miles south of Grand'Mère, on range St. Mathieu and known as the Proulx Block.

The soil consists of old marine sand deposits of low fertility, moisture regime, and nutrient levels. Lack of an organic layer accentuates the waterdeficit in the upper soil, and the capillary tensions in the coarse underlying sand are certainly not great enough to lift water to the root zone.

A continuous carpet of Cladonia rangiferina (L.) Web. and Polytrichum commune Hedw., whose moisture capacity is reported by Beall ${ }^{2}$ to be extremely low compared to other mosses or lichens, covers this flat area of dry sand.

The trees, growing sparsely and without competition, are exposed to excessive transpiration. Root development is confined to the upper 10 inches of soil. In a similar condition, Paine ${ }^{8}$ recorded a maximum temperature of $73^{\circ}$ at a depth of 8 inches.

\section{Field}

The growth ring analysis was made on 43 cross sections from dominant trees taken at 6 inches above ground level. Cross section diameters ranged from 3.8 to 5.6 inches. Dominant trees of roughly similar size were selected in an attempt to obtain responses to environmental factors that would be of a nature that would permit comparisons.

\section{Office}

The transverse stump sections were brought into the laboratory, smoothed, and, in the second method, with 17 observations possible out of 18 years' data, annual ring was measured to the nearest $1 / 60$ inch along an average radius. Weather data were obtained from a meteorological station at Shawinigan, about 5 miles west of the area studied.

Several tests were made to find a relationship between ring width and rainfall for the months of May, June, July, August, and September of the current and the preceding year, taken separately or in various combinations. Of these, only rainfall of June, July, and August, of the preceding year, showed a consistent relationship with ring growth. The total amount of rainfall during these months was then computed.

To eliminate the influence of monthly (random) rainfall (Schumacher and Day, 1939) upon the coefficient of correlation, also because in the region studied soil moisture during the month of July is not affected by melting snow as in June, and most of the diameter growth is completed by the end of July, the second intermediates ${ }^{4}$ were computed and the coefficient of correlation calculated from them. Emphasis was then placed upon July precipitation.

\footnotetext{
Personal communication with $H$. W. Beall, Department of Forestry, Ottawa.

${ }^{3}$ Personal communication with Dr. L. E. Paine, former Research Officer with Forest Biology Laboratory, Quebec, P.Q.

- The average of the sum of twice the measurements for the month of July plus the measurements for the preceding and succeeding months (after Douglass, 1936 and Schumacher, 1939).
} 


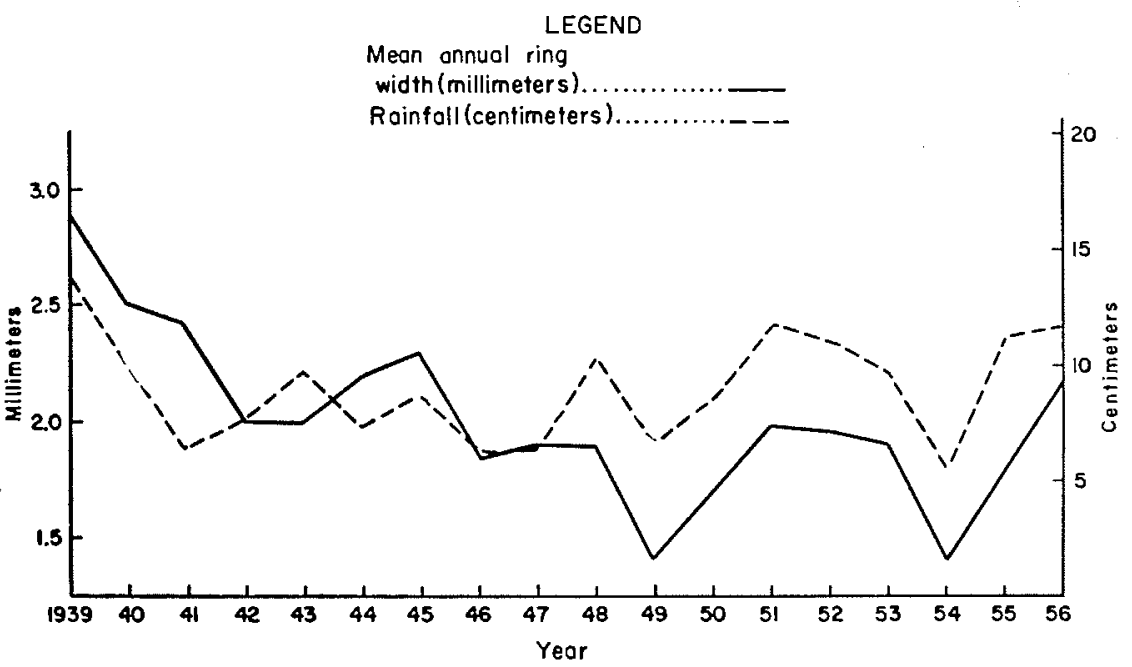

FIGURE I. The relationship between mean annual ring width and mean monthly rainfall for June-July-August of previous year.

\section{RESULTS}

Fluctuations in mean annual ring width of 43 dominant trees over a period of 18 years are compared in Figure 1 with the mean monthly precipitation in June, July, and August of the previous year.

Two statistical methods of showing the degree of relationship between rainfall and ring increment were used; the first involved calculation of the correlation coefficient and the second the comparison of graphs as described by Daubenmire (1955). In both cases the relationship was evident. In the first method the coefficient of correlation was significant at the 2 per cent level, and, in the second method, with 17 observations possible out of 18 years' data, the number of agreements was 13 . According to the method outlined by Daubenmire (1955) this number of agreements exceeds the value of 12 required for possible significance.

It must, here, be pointed out that different views upon the use of statistics for the elucidation of such a relationship have been expressed by various authors. Many after Douglass (1936), Schumacher and Day (1939), and Hustich (1948) still use the coefficient of correlation. Others, with Glock (1941), Primault and Kuhn (1954) are opposed to this method while some along with Shreve (1924), Lyon (1943), and Daubenmire (1955) favour a comparison of graphs to establish relationships in time sequence. Discussions of the various methods are beyond the scope of this paper and references are made herein to both methods of compilation.

\section{Discussion}

In interpreting the positive correlation between current ring width and (yearly) summer rainfall fluctuations of the previous year, one must remember that the considerable growth, which occurs in the spring, is largely dependent 
upon food stored the previous summer. Moreover, physiological processes are multi-conditioned and, often, similar growth patterns can be produced by different combinations of several factors. However, there can be cases where rough parallels between mean ring width and one isolated factor, such as rainfall of the preceding summer, could be observed especially on dry sites where the low soil moisture seems to influence some processes which have a direct effect on diameter growth.

Considerable uncertainty exists concerning the extent to which soil moisture must be depleted before growth is reduced. In summer, transpiration is known to exceed absorption (Clark and Gibbs, 1957) resulting in a tendency toward an unfavourable internal water balance in the tree. Any variation in soil water content will doubtless have some bearing on next year's growth by its favourable or unfavourable influence on the availability of solutes (Volk, 1934) and the efficiency of absorption at a time when reserve foods for future growth are being accumulated. On sandy sites, such as those at Grand'Mère, soil water variation is entirely a function of rainfall.

However, it must be pointed out that food reserves found in conifers are also of an organic nature chiefly resulting from the efficacy of photosynthesis and from the translocation of carbo-hydrates, and a considerable amount of these nutrients is being stored during summer. Clark ${ }^{5}$ mentioned that the amount of carbo-hydrates used in respiration is about $1 / 6$ to $1 / 10$ of what is produced. For this reason, the possibility that other growth factors may act jointly with rainfall is not eliminated.

The lack of agreement between rainfall of the previous year and current ring width for the years of 1942, 1943 and 1944 cannot be explained; correspondence (not illustrated) between the amount of rainfall and its distribution over the same period was also noted. It may be that other environmental factors, such as temperature, relative humidity, wind, etc., are responsible for those atypical years, but owing to lack of clear and reliable data for these factors, speculation is unwarranted. Results for these atypical years show the necessity of using a long period of years to establish the relationship between rainfall and growth in time sequence.

Doubtless, current rainfall has a certain influence upon the current rate of tree growth but, at Grand'Mère, where an organic layer is lacking, the local soil moisture content which prevails during most of the growing seasons tends to nullify the effect of precipitation on current growth. In this region there is still snow on the ground in May and effects from melting snow endure until approximately mid-June, at which time considerable current growth is already completed. Detailed investigations (not illustrated) to establish a relation between total current growth and current monthly rainfall over at least 18 years have proved futile. The results might have been different if, for the months of July and August, the monthly current growth had been opposed to the corresponding monthly rainfall, but this was impossible at Grand'Mère since stump sections of trees already cut for other experiments were used.

It is obvious that in cold regions where precipitation is high but where the forest soils are covered with an organic layer, whose water-holding capacity

\footnotetext{
${ }^{5}$ Communication from J. Clark, Forest Biology Laboratory, Fredericton, N.B.
} 
is high, the amount of water that is available for tree growth cannot be expressed in terms of annual precipitation alone. In these conditions, the quality of the water absorbed by the roots more than the actual amount of rainfall should influence the tree growth. However, under the conditions described, it appears from examination of Figure 1 that summer rainfall exerts some of its beneficial effects on next year's diameter growth of white spruce. In respect of height growth, it is interesting to note that many workers have reached similar conclusions for different tree species under different soil conditions. (Bell, 1956; Duff and Nolan, 1953; Kienholz, 1934; Motley, 1949.)

\section{Summary AND CONCLUSIONS}

The annual variations in summer rainfall of the previous growing season have been compiled for a dry site of low fertility on a 3-acre experimental area at Grand'Mère, Quebec, for the 1939-1956 period. Correlations were made between these data and the current radial growth taken at 6 inches above ground level on 43 dominant white spruce growing without competition. Two methods of analysis to show such a relationship have been used; the coefficient of correlation, and the comparison of graphs. Both revealed a close relationship between current diameter growth and summer rainfall of the previous growing season. Interpretation of such a relationship is discussed in the light of soil moisture variations prevailing during the period of food accumulation for the succeeding year's growth.

Results of this study provide further evidence that under certain local soil conditions the current annual ring width of some tree species may be affected, at least indirectly, by total rainfall which occurs during the food storage season. Consequently, when estimating current growth of white spruce on poor sandy soils in relation to environment, particular attention must be given to the rainfall fluctuations of the previous summer.

\section{ACKNOWLEDGEMENT}

The author wishes to express his appreciation to Dr. J. Clark of the Forest Biology Laboratory at Fredericton, New Brunswick, to Drs. J. S. Rowe and I. C. M. Place of the Department of Forestry, to Professor A. Lafond for suggestions in reviewing the paper, and to Dr. A. Linteau, Messrs. J. D. MacArthur and R. J. Hatcher for their assistance in preparing the manuscript for publication. The author is also grateful to Mr. A. Choquette, Forest Assistant, for securing field and laboratory data.

\section{REFERENCES}

BELL, D. B. 1956. The relationship between height growth in conifers and the weather. Edited by Dr. L. Leyton, Oxford University, England. (From a thesis submitted as part of requirements of the Honour School of Forestry).

CLARK, J. and R. D. GIBBS. 1957. Studies in tree physiology. IV. Further investigations of seasonal changes in moisture content of certain Canadian forest trees. Canad. J. Bot. 35: 219-253.

DAUBENMIRE, R. F. 1955. Xylem layers of trees as related to weather and altitude in the northern Rocky Mountains. Ecology 36: 456-463.

DOUGLASS, A. E. 1936. Climatic cycles and tree-growth. Carneg. Instn. Wash. Publ. 289. Vol. III, p. 18. 
DUFF, G. H. and N. J. NOLAN. 1953. Growth and morphogenesis in Canadian forest species. Canad. J. Bot. 31: 471-513.

FRITTS, H. C. 1958. An analysis of radial growth of beech in a central Ohio forest during 1954-55. Ecology 39: 705-720.

GLOCK, W. S. 1941. Growth rings and climate. Bot. Rev. 7: 649-713.

GLOCK, W. S. 1955. Growth rings and climate. Bot. Rev, 21: 73-188.

HUSTICH, I. 1948b. Tree growth and climatic fluctuations. Eripainos Terrasta No. 2, 73-80. Cited from Bot. Rev. 21: 158. 1955.

KIENHOLZ, R. 1934. Leader, needle, cambial and root growth of certain conifers and their interrelations. Bot. Gaz. 96: 73-92.

KRAMER, P. J. and T. T. KOZLOWSKI. 1960. Physiology of trees. McGraw-Hill (Edmund W. Sinnott, Consulting Editor.)

LYON, C. J. 1943. Water supply and growth rates of conifers around Boston. Ecology 24: 329-344.

MOTLEY, J. A. 1949. Correlation of elongation in white and red pine with rainfall. Butler Univ. Bot. Stud. 9: 1-8 (Indianapolis, Ind.)

PRIMAULT, B. and W. KUHN. 1954. De l'opportunité d'utiliser les coefficients de corrélation en météorologie forestière. Geofisica Pura e. applicata-Milano. 28: 246-260.

SAMPSON, A. W. and W. S. GLOCK. 1942. Tree growth and the environmental complex: a critique of "Ring" growth studies with suggestions for future research. J. For. 40: 614-620.

SCHUMACHER, F. X. and B. DAY. 1939. The influence of precipitation upon the width of annual rings of certain timber trees. Ecol. Monogr. 9: 387-429.

SHREVE, F. 1924. Growth in trees and massive organs of plants. The growth record in trees. Carneg. Instn. Wash. Publ. 350.

TRYON, E. H., J. O. CANTRELL, and K. L. CARVELL. 1957. Effect of precipitation and temperature on increment of yellow poplar. Forest Sci. 3: 32-44.

VOLK, N. J. 1934. The fixation of potash in difficultly available form in soils. Soil Sci. 37: 267-287.

WEIHE, J. 1959. Correlations between height and diameter growth of spruce and their dependence on precipitation and temperature. Allg. Forst-u. Jagdztg. 130 (1), 1959. Cited from Forestry Abstracts 20(3593): 441. 1959. 